\title{
Growth responses of Betula pendula ecotypes to red and far-red light
}

\author{
Berhanu A. Tsegay * \\ Department of Biology \\ Bahir Dar University, Ethiopia \\ Tel: 2518206208 (home) \\ Fax: 2518202025 \\ E-mail: berhanutsegay@yahoo.com \\ Leidulf Lund \\ Department of Biology \\ Faculty of Science, University of Tromsø \\ N-9037 Tromsø, Norway \\ Tel: 4777644904 \\ Fax: 4777644898 \\ E-mail: leidulf.lund@ib.uit.no \\ Jarle Nilsen \\ Department of Biology \\ Faculty of Science, University of Tromsø \\ N-9037 Tromsø, Norway \\ Tel: 4777644899 \\ Fax: 4777646333 \\ Jorunn E. Olsen \\ Department of Plant and Environmental Sciences \\ Agricultural University of Norway \\ P.O. Box 5003 \\ N-1432 Aas, Norway \\ Tel: 4764965000 \\ Fax: 4764947505 \\ Jorgen M. Molmann \\ Department of Biology \\ Faculty of Science, University of Tromsø \\ N-9037 Tromsø, Norway \\ Tel: 4777644445 \\ Fax: 4777646333 \\ E-mail: jorgen.molmann@ib.uit.no
}

\section{Arild Ernsten $^{\dagger}$}

Department of Biology

Faculty of Science, University of Tromsø

N-9037 Tromsø, Norway

\section{Olavi Juntttila}

Department of Biology

Faculty of Science, University of Tromsø

N-9037 Tromsø, Norway

Tel: 4777644430

Fax 4777646333

E-mail: olavi.junttila@ib.uit.no

Financial support: This research was funded by the Norwegian Research Council.

Keywords: diode, ecotype, monochromatic, photomorphogenesis, phytochrome, photosynthetically active radiation (PAR).

Abbreviations: R: red light;

FR: far red light;

PAR: photosynthetically active radiation;
Pr: red light perceiving phytochrome;

SDs: short days;

LDs: long days.

\footnotetext{
* Corresponding author
} 
The effect of Red light (R), Far-red light (FR) and R/FR combinations on shoot growth of latitudinal ecotypes of B. pendula was studied using special diodes that emit monochromatic lights. When a 12 hrs PAR (110 $\mu \mathrm{mol}$ $\mathrm{m}^{-2} \mathrm{~s}^{-1}$ ) was extended with $R, F R$ or $R / F R$ ratios, lower intensities of monochromatic lights could not prevent growth cessation. At $25 \mu \mathrm{mol} \mathrm{m} \mathrm{m}^{-1}$, FR compared to $\mathrm{R}$ enhanced stem elongation in all ecotypes. This was due to the inhibitive effect of $R$ on internode elongation. When day-length was extended by $R / F R$ at various ratios, there was continuous shoot elongation, but was found to be declining with increasing ratios. The more the $R$, the shorter were the internodes of each plant. $B$. pendula ecotypes produced branches when PAR light during the day was extended by incandescent light, but did not do so when the light extensions were made by monochromatic $\mathbf{R}$ or $F R$ or their combination. Branching increased with decreasing latitude of the ecotype.

Light, as a main environmental trigger, plays a central role in regulating plant development. Most terrestrial plants grow by selective absorption of natural light from the sun. The most effective components of the spectrum of light are red (R), far-red (FR), and blue. These lights are involved in the regulation of photosynthesis, pigment biosynthesis, photoperiodism, phototropism, and photomorphogensis. The photomorphogenetic response of plants to light include, among others, seed germination, inhibition of hypocotyl elongation, cotyledon and leaf expansion, pigment synthesis, stem elongation, and induction of flowering (Weller et al. 2000).

At least three known photoreceptor proteins monitor the quantity and quality of the incoming light. These are the phytochromes, the cryptochromes and phototropins, as well as the UV-B photoreceptors. Phytochromes are the most studied of these receptors. They are soluble chromoproteins synthesized in the dark, in their physiologically inactive form, red light perceiving phytochrome (Pr). Upon irradiation with $\mathrm{R}$, phytochromes are converted to their active form, far red light perceiving phytochrome (Pfr), which in turn decay back to, or are photolytically reconverted by FR to the original inactive form, Pr. This cyclic reversibility enables plants to respond, among others, to changes in spectral composition of light and to optimise growth and development during their whole life cycle. In Arabdopsis, there are at least five genes (PHYA to PHYE) encoding five groups of phytochromes, phyA to phyE (Hauser et al. 1997; Gil et al. 2000; Weller et al. 2000). These phytochromes monitor a wide array of light parameters, including the onset of light, the directional vector of ambient light, the ratio of $\mathrm{R}$ to $\mathrm{FR}$, a range of photon fluences and the wavelength distribution of light during the day as well as at the end of the photoperiod (Hauser et al. 1997; Olsen and Junttila, 2002). The most studied phytochromes are phytochrome A (phyA) and phytochrome $\mathrm{B}$ (phyB). PhyA mediates the very low fluence response (VLFR, under multiple wavelengths of light) and high irradiation response (HIR, under continuous FR). PhyB is responsible for the R/FR - reversible low fluence response, LFR (Chory, 1997).

In temperate zone woody plants, short days (SDs) induce growth cessation and bud dormancy. However, when SDs are extended with light extensions of appropriate spectral composition, plants perceive them as long days (LDs). Such perception depends on the light requirement of those plants under consideration. Latitudinal ecotypes of northern tree species have different responses to light quality (Håbjørg, 1972; Junttila and Kaurin, 1985; Clapham et al. 1998), which could indicate differences in composition of their phytochrome systems. In experiments using light sources enriched in $\mathrm{R}$ or FR light, differences in FR light requirement by latitudinal ecotypes have been indicated. For example, in Salix pentandra, high R/FR ratio during the night extension did not produce a LD effect in a northern ecotype but did so in a southern one (Junttila and Kaurin, 1985). Moreover, over-expression of phyA changed (shortened) the critical photoperiod of hybrid aspen (Olsen et al. 1997). However, such responses have not been tested with monochromatic lights or defined R/FR ratios. $B$. pendula ecotypes grow continuously when 12 hrs PAR light is extended with incandescent bulbs of about $10 \mu \mathrm{mol}$ $\mathrm{m}^{-2} \mathrm{~s}^{-1}$ (Berhanu, 2002). But, the responses of the latitudinal ecotypes upon extension of the PAR light with R, FR or various ratios of $\mathrm{R}$ and $\mathrm{FR}$ have not been studied. Moreover, there is no information so far about possible differences between photoperiodic ecotypes at the phytochrome level although phytochrome genes have been cloned from both conifers and deciduous species.- This study aimed at comparing the vegetative growth responses of latitudinal ecotypes of $B$. pendula to monochromatic R and FR, and to various combinations of $\mathrm{R}$ and FR.

\section{MATERIALS AND METHODS}

\section{Light treatments}

Light emitting diodes (Q-BEAM 2200, Quantum Devices, Inc. 112 Orbison Barneveld, WI 53507, USA) were used as sources of $\mathrm{R}$ and FR lights. In these light sources, both irradiances and R: FR ratios could be changed independently. Photon fluence rates of $\mathrm{R}$ with maximum emission at about $667 \mathrm{~nm}$ were measured using a Datalogger (Model L $\mathrm{L}_{1}-1000$ Serial No. LDL 3527, USA) with the light sensor, LI-CDR Quantum, Q2012 attached to it. Fluence rates of FR at maximum emission of $739 \mathrm{~nm}$ were adjusted in relation to the quantified $\mathrm{R}$. These light treatments were established in trolleys each having a size of $50 \times 50 \mathrm{~cm}$. The light source heads of the LEDs were mounted on a board at about the top-centre of each trolley, providing almost uniform intensities at various parts of the trolleys. A fourth trolley was prepared for dark control. All 
Table 1. Analysis of the variance of stem elongation of latitudinal ecotypes of $B$. pendula showing the main effects of ecotype, irradiance, light quality, and the interactions between them.

\begin{tabular}{|l|c|c|c|c|c|}
\hline \multicolumn{1}{|c|}{ Source of variation } & DF & Sum of squares & Mean square & F-Value & P-Value \\
\hline Ecotype & 2 & 3601.6 & 1800.8 & 3.032 & 0.0670 \\
\hline Irradiance & 3 & 78242.6 & 26080.9 & 43.913 & $<0.0001$ \\
\hline Light Quality & 1 & 18177.0 & 18177.0 & 30.605 & $<0.0001$ \\
\hline Ecotype - Irradiance & 6 & 2352.170 & 392.028 & 0.660 & 0.6622 \\
\hline Ecotype - Light Quality & 2 & 1340.6 & 670.293 & 1.129 & 0.3401 \\
\hline Irradiance - Light Quality & 3 & 5251.633 & 1750.544 & 2.947 & 0.0532 \\
\hline Ecotype - Irradiance - Light Quality & 6 & 731.854 & 121.976 & 0.205 & 0.9717 \\
\hline Residual & 24 & 14254.008 & 593.917 & \\
\hline
\end{tabular}

trolleys were covered on all sides by curtain to prevent possible entrance of light beams from one trolley to the other.

Photosynthetically active radiation, about $110 \mu \mathrm{mol} \mathrm{m} \mathrm{m}^{-2}$, was made available by installing fluorescent lamps (Phillips TLD 58/840) in each trolley (Figure 1). This was made by adjusting the distance between the lump and the shoot apices. Hence, all plants were treated with PAR light for 12 hrs and with R, FR, R/FR or dark for the other 12 hrs of each day. Effects of monochromatic R and FR on cessation of growth of seedlings were studied at intensities of 0.5 , 1.0, 9.5, and $25.0 \mu \mathrm{mol} \mathrm{m} \mathrm{m}^{-2} \mathrm{~s}^{-1}$. Various R: FR ratios (1.0, $1.5,2.0,2.5,3.0,5.0$, and 7.5$)$ at $25 \mu \mathrm{mol} \mathrm{m}^{-2} \mathrm{~s}^{-1}$ were also used in these growth cessation experiments.

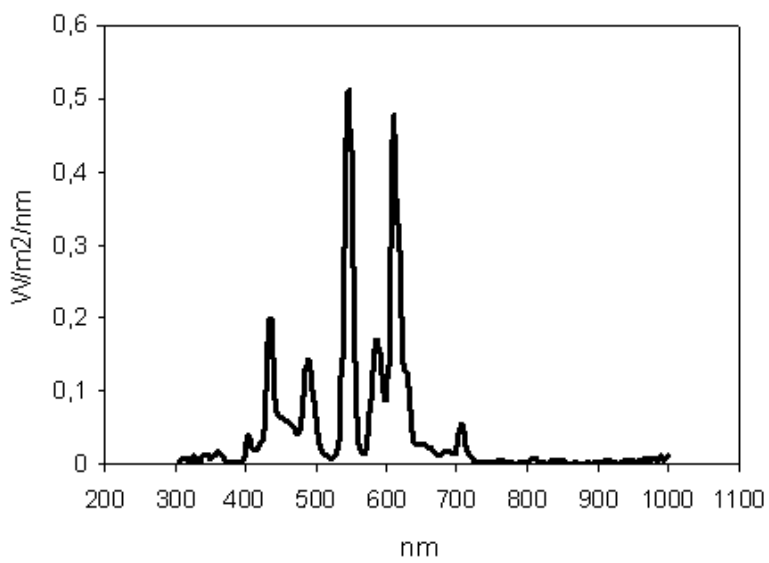

Figure 1. Spectral photon distribution of the fluorescent lamps (Phillips TLD 58/840) used in the growth chambers (trolleys).

\section{Plant material and growth conditions}

This experiment was conducted in the phytotrone, the University of Tromsø. Seedlings of three latitudinal ecotypes of $B$. pendula Roth were used. Seeds were collected from southern Norway $\left(59^{\circ} \mathrm{N}\right)$, the middle of Norway $\left(64^{\circ} \mathrm{N}\right)$ and northern Norway $\left(67^{\circ} \mathrm{N}\right)$. The seeds were stratified in moist sand for about a month at $0.5^{\circ} \mathrm{C}$ and germinated in continuous light $\left(180-200 \mu \mathrm{mol} \mathrm{m}^{-2} \mathrm{~s}^{-1}\right)$ from fluorescent tubes (Philips TLD 58 / 840) and incandescent bulbs at $18^{\circ} \mathrm{C}$. After germination, seedlings were transplanted into $12 \mathrm{~cm}$ diameter pot, 4 to 5 plants per pot. The growth medium was fertilized peat: perilite: and sand $(6: 3: 1, \mathrm{v} / \mathrm{v})$. Plants were watered daily with a complete nutrient solution (Junttila, 1980). Day-length treatments were established in the phytotrone compartments. The main light period of $12 \mathrm{hrs}\left(08: 00\right.$ - 20:00) had $150 \mu \mathrm{mol} \mathrm{m} \mathrm{s}^{-2}$ PAR from fluorescent tubes and additional $10 \mu \mathrm{mol} \mathrm{m} \mathrm{m}^{-2} \mathrm{~s}^{-1}$ from incandescent bulbs. The photoperiodic treatments were established by extending the light period with 10 $\mu \mathrm{mol} \mathrm{m} \mathrm{m}^{-2} \mathrm{~s}^{-1}$ light from incandescent bulbs (Osram, $75 \mathrm{~W}$ ). Temperature in the compartments was $18 \pm 0.5^{\circ} \mathrm{C}$ and the RH was $78 \%$, which corresponds to $0.5 \mathrm{kPa}$ water vapour pressure deficit. When the plants reached the size of 2 to 3 $\mathrm{cm}$, they were transferred to their respective light treatments (12 hrs PAR +12 hrs extension with R, FR, $\mathrm{R} / \mathrm{FR}$ or dark). There were four pots per treatment per ecotype, each pot containing 4 plants. Stem length and numbers of new leaves were recorded every week for one month.

\section{Statistical analyses}

Statistical analyses were carried out using Abacus Concepts (Haycock et al. 1994), Stat View (Abacus Concepts, Inc., Berkeley, CA, 12994). Standard deviations or standard errors were presented. 


\section{RESULTS}

\section{Growth cessation}

About 2 - $3 \mathrm{~cm}$ long plants, which had been grown in LD of 12 hrs PAR plus 12 hrs incandescent light were treated by 12 hrs PAR extended with 12 hrs R, FR at various intensities, or R/FR at various ratios for 4 weeks.

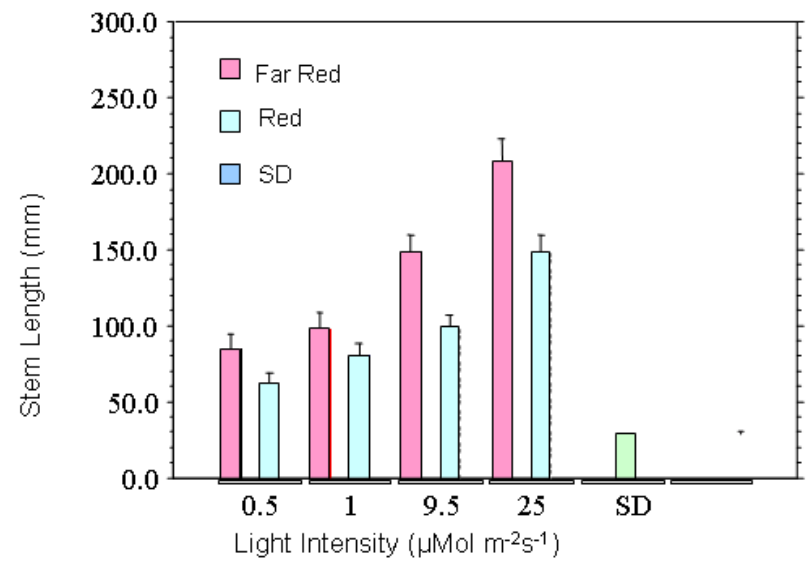

Figure 2. Stem elongation when a $12 \mathrm{hrs}$ PAR light $(110 \mu \mathrm{mol} \mathrm{m}$ $2 \mathrm{~s}^{-1}$ ) was extended for $12 \mathrm{hrs}$ with monochromatic R or FR at different irradiances. In SD control, 12 hrs of PAR light was extended with $12 \mathrm{hrs}$ darkness. Each point is an average of 16 plants that have been under experimental condition for one month. Standard deviations at the end of the experiments are shown.

Generally, the intermediate ecotype grew slower than the other ecotypes. Average growth increment, means of all $\mathrm{R}$ and FR irradiances, was $129 \pm 12.4,108 \pm 14.6$, and $121 \pm$ $11.6 \mathrm{~mm}$ for the southern, intermediate, and northern ecotype, respectively. Differences between these values were not, however, statistically significant. As shown in Fig 2., FR (compared to R) enhanced stem elongation in all ecotypes. The difference between the effect of FR and R at the two highest irradiances was highly significant $(\mathrm{P}<$ 0.0001). Growth increment during the experiment, as a mean of all ecotypes and irradiances, was $139 \pm 11.2$ and $100 \pm 8.1 \mathrm{~mm}$ for FR and R, respectively. These values were different at $P=0.007$. Stem elongation increased with increasing irradiance both for R and FR. Although the two lowest irradiances, 0.5 and $1.0 \mu \mathrm{mol} \mathrm{m} \mathrm{m}^{-2} \mathrm{~s}^{-1}$, enhanced growth compared to $\mathrm{SD}$, they could not prevent cessation of elongation growth (Figure 2). At irradiances of 9.5 and 25.0 $\mu \mathrm{mol} \mathrm{m} \mathrm{m}^{-2} \mathrm{~s}^{-1}$, elongation growth was sustained in all ecotypes both by FR and R day-length extensions. Besides, there was no statistically significant interaction between ecotype and light quality or irradiances (Table 1).

Light quality had significant influence on internode length but not on the number of leaves. However, leaf number increased with increasing irradiance (Figure 3). The mean leaf number of all ecotypes at all irradiances was 4.2 and
4.8 in FR and R, respectively. These values are statistically similar $(\mathrm{P}=0.2962)$. The northernmost ecotype had less number of leaves compared to the southernmost.
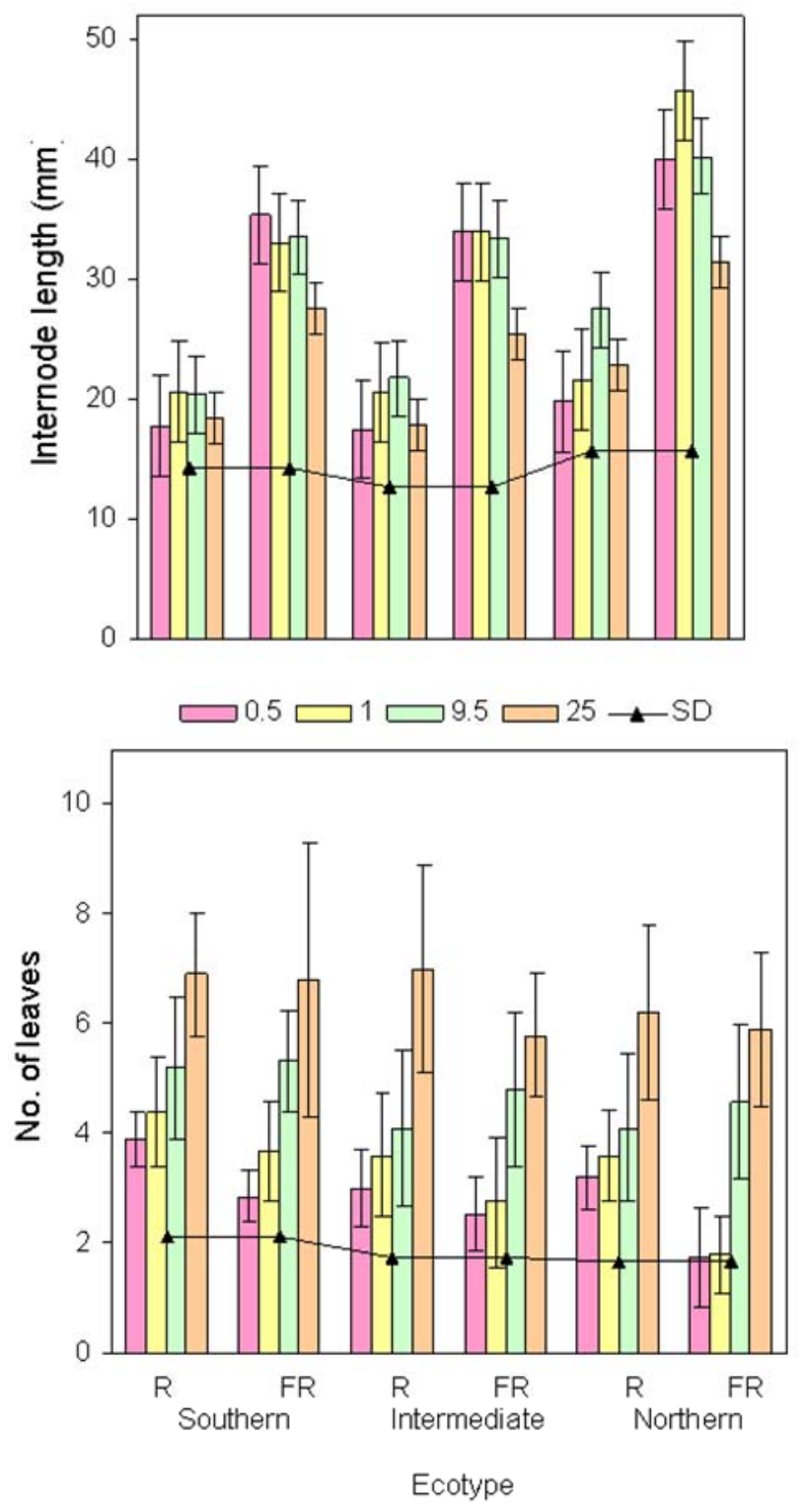

Figure 3. Effect of light quality on internode length of latitudinal ecotypes of $B$. pendula Roth. All growth conditions and number of plants per treatment were as given on. Error bars show 95\% confidence interval.

When 12 hrs PAR light was extended by various R/FR ratios, shoot growth (stem elongation and production of new leaves) was continuous in all treatments. The mean stem elongation of all treatments was $215 \pm 7.4,159 \pm 6.1$ and $208 \pm 8.5 \mathrm{~mm}$ for the southern, the intermediate and the northern ecotype, respectively. The intermediate ecotype was responding differently from the other two $(\mathrm{P}<0.0001$; 
critical difference of 17.47). Although stem elongation was continuous, the rate of growth declined with increasing $\mathrm{R} / \mathrm{FR}$ ratios, especially in the southern and the northern ecotypes (Figure 4a). The mean values of elongation growth of all ecotypes were $182 \pm 9,238.9 \pm 15.7,207 \pm$ 16.5, $199 \pm 17.2,192 \pm 14.5,199 \pm 16.1,178 \pm 8$, and 156 $\pm 6.7 \mathrm{~mm}$ in R/FR of $0.5,1.0,1.5,2.0,2.5,3.0,5.0$, and 7.5 , respectively. Stem lengths at the lowest (0.5) and two highest (5.0 and 7.5) R/FR ratios were significantly shorter $(\mathrm{P}<0.05)$ than in ratios of 1.0 - 3.0. In R/FR ratios of 1.0 3.0, growth was almost identical to LD control in the southern and the northern ecotypes (data not given). No significant effect of $\mathrm{R} / \mathrm{FR}$ ratios on production of new leaves was detected (Figure 4b). Consequently, internode length decreased with increasing R/FR ratio (Figure 4c). Regression of internode length against R/FR ratio was highly significant (see equations on Figure 4c).

Another observation made during the experiments was that the branching pattern was dependent on the light treatment and on the ecotype. Plants grown in LDs ( 12 hrs PAR +12 hrs incandescent) produced branches while there was no branching in those treatments where the day-length extension was made by monochromatic R or FR, or their combination (Figure 5). Moreover, rate of branching decreased with increasing latitude of the ecotype.

\section{DISCUSSION}

Extension of 12 hrs PAR light with 12 hrs FR or R at 0.5 or $1.0 \mu \mathrm{mol} \mathrm{m} \mathrm{m}^{-2} \mathrm{~s}^{-1}$ could not prevent cessation of growth in $B$. pendula ecotypes. At irradiances of 9.5 and $25.0 \mu \mathrm{mol} \mathrm{m}{ }^{-2}$ $\mathrm{s}^{-1}$ growth was sustained, but the seedlings at $\mathrm{R}$ had stunted growth compared to those treated with FR (Figure 2). When the plants were irradiated with different R/FR ratios, they were able to grow continuously. These results essentially proved the combined effect of the putative light receptors, phyA and phyB. The northernmost ecotype had longer internodes than the southern ones (Figure 3). However, the total stem length was not different from the southernmost ecotype (Figure 2). Hence, the requirement of FR at the tested irradiances was similar to all ecotypes. Moreover, none of the R/FR ratios used stopped growth. However, there was a declining rate of stem elongation with increasing R/FR ratio (Figure 4a). Unlike stem elongation, the number of leaves remained constant in all R/FR ratios (Figure 4b). Consequently, there was a sharp decline in internode length with increasing R/FR-ratio (Figure 4c). R/FR-ratios between 1 and 3 (inclusive) resulted in best growth in all ecotypes, comparable to growth of those plants grown in LD PAR light extended with incandescent light, R/FR = ca. 0.7.

Differences in FR light requirement for growth extension were shown by latitudinal ecotypes of Salix pentandra (Junttila and Kaurin, 1985), Picea abies (Clapham et al.

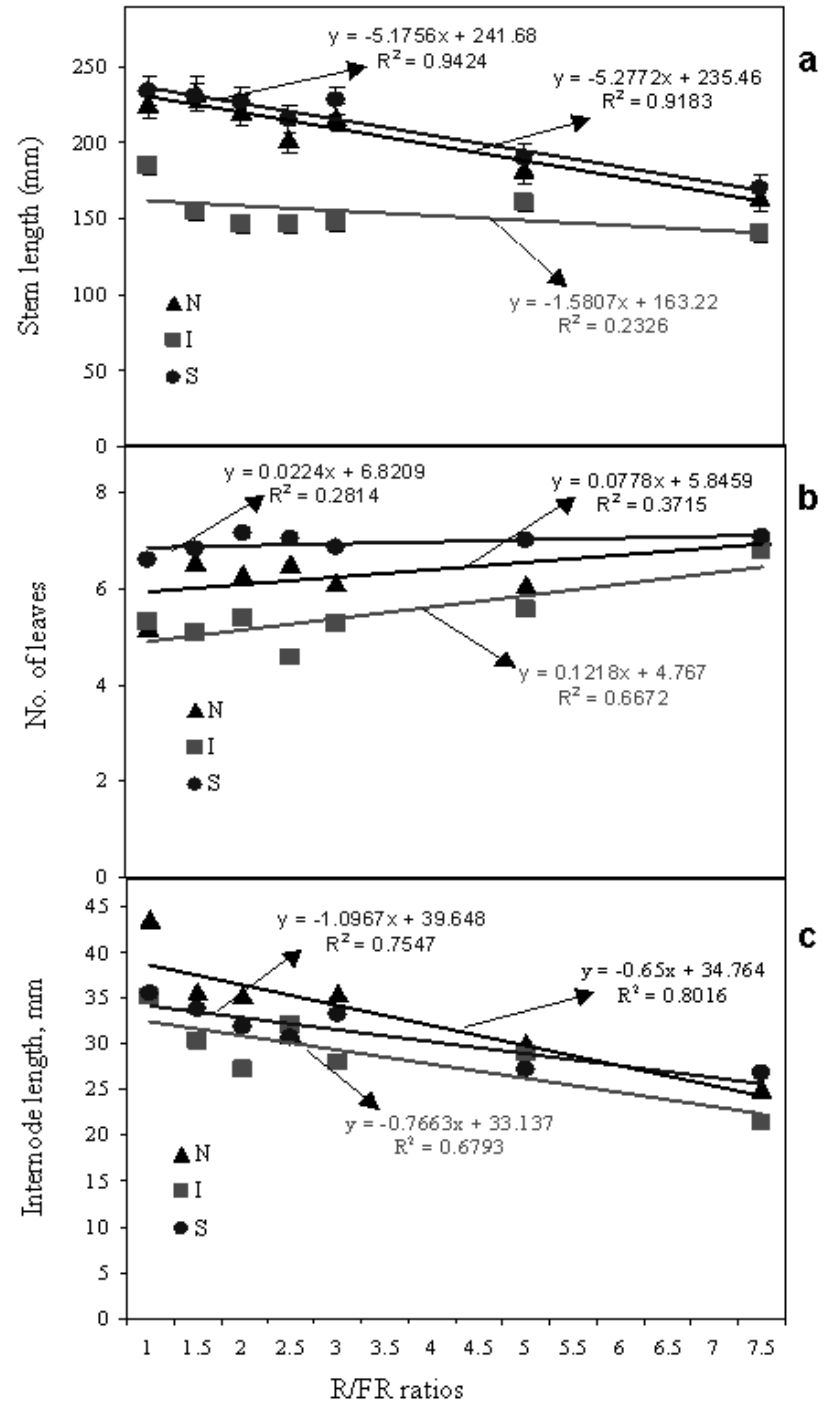

Figure 4. Effect of R:

(a) FR ratios on stem length;

(b) Production of new leaves; and

(c) Internode length in latitudinal ecotypes of $B$. pendula.

About 2 - 3-cm long plants, which had been growing in LDs, were transferred to various R/FR treatments. In each treatment, $12 \mathrm{hrs}$ of PAR was extended by $12 \mathrm{hrs}$ of different R/FR ratios at an irradiance of $25 \mu \mathrm{mol} \mathrm{m} \mathrm{m}^{-2} \mathrm{~s}^{-1}$. Each point is a mean of 16 plants. Mean \pm S.E. are shown. ( $\mathrm{N}$ - northern, I - intermediate, $\mathrm{S}-$ southern).

1998) and Pinus sylvestris (Clapham et al. 2002). When the day-length was extended with FR-poor lamps, the southern ecotypes (south of $61-64^{\circ} \mathrm{N}$ ) continued to grow while the northern ones ceased growth. This was not the case in $B$. pendula ecotypes used in this study. As FR decreased $(\mathrm{R} / \mathrm{FR}=7.5)$, extension growth was reduced, but all ecotypes behaved similarly. Furthermore, the reduced elongation was due to the decline in internode elongation. Although the explanation may not be easy at this point, it is worth mentioning some possible reasons. The first possibility is the very difference of the plant species. While 
it is logical to expect $B$. pendula to behave in a similar way to Salix pentandra, the other species, Picea abies and Pinus sylvestris are phylogenetically far away from $B$. pendula. Besides, the treatment of the latter two was 8 hrs PAR and 16 hrs FR-poor day extension. The second possible factor may be the intensity of the light treatment. While Clapham et al. 2002 used $230 \mu \mathrm{mol} \mathrm{m} \mathrm{m}^{-2}$ from incandescent during $8 \mathrm{hrs}$ day and extended it by $16 \mathrm{hrs}$ of $40 \mu \mathrm{mol} \mathrm{m}^{-2} \mathrm{~s}^{-1}$ from FR-poor white fluorescent light, in this experiment 110 $\mu \mathrm{mol} \mathrm{m} \mathrm{m}^{-2} \mathrm{~s}^{-1}$ from fluorescent tubes during $12 \mathrm{hrs}$ day was extended by $25 \mu \mathrm{mol} \mathrm{m} \mathrm{m}^{-1}$ FR only or R/FR at various ratios from light emitting diodes.

When a 12 hrs PAR $\left(150 \mu \mathrm{mol} \mathrm{m} \mathrm{s}^{-2}\right.$ plus $\left.10 \mu \mathrm{mol} \mathrm{m}^{-2} \mathrm{~s}^{-1}\right)$ was extended by incandescent light $\left(10 \mu \mathrm{mol} \mathrm{m}^{-2} \mathrm{~s}^{-1}\right)$ there was branching by most plants of the southern and the intermediate ecotypes. Branching increased with decreasing latitude of the ecotypes (Figure 5). This phenomenon could be due to light spectra other than $\mathrm{R}$ and FR in the incandescent light, especially blue light. Induction of side branching by blue light in a moss Physcomitrella patens protonemal colonies was reported by Imaizumi et al. (2002). The induction of side branching was believed to be a result of the suppression of auxin induced gene expression by cryptochrome-mediated signals. In the classical blue light induced phototropism of shaded and illuminated coleoptiles of cereals (Taiz and Zeiger, 1998), bending is believed to be the result of the lateral redistribution of auxin (caused by blue light) and differential rates of cell elongation. The increased of branching in mixed lights (incandescent light) and the absence of branching in $\mathrm{R}, \mathrm{FR}$ or $\mathrm{R}+\mathrm{FR}$ treated plants in this experiment may give clue to the role of blue light in inducing branches in trees as well. If this is true, the response to the signal by the different ecotypes of $B$. pendula was different: decreasing with increasing latitude of origin.

Of the $B$. pendula ecotypes used in this study, the intermediate one was behaving differently (had slower growth rate) from the southern and the northern ones. Thus, it is likely that these differences were because of other factors than the latitudinal origin of the ecotype. For example, it is possible that differences in seed lot (storage) could have affected photomorphogenesis of the seedlings. Another factor that could interfere in the growth and development of seedlings is the climatic and nutritional status of the mother plants. If the growth environment of the mother plants were favourable, the seeds would properly mature and store enough food, which, in turn, directly influences the success of germination and development of the seedlings. It is also possible that the seed lot of the intermediate ecotype does not fully (completely) represent the ecotype genetically. While studying the adaptive properties of Picea abies progenies, Johnsen and Skrøppa (1996) concluded that both the genetic constitutions of the parents and the prevailing environmental conditions during sexual reproduction could alter the phenotypic performance of the progenies. They further elaborated this issue and put the reproductive environment to be additional evolutionary force to mutation, natural selection and gene flow (Johnsen et al. 1996; Skrøppa and Johnsen, 2000). Thus, the phenotypic anomality of the intermediate ecotype might have been caused by several factors.

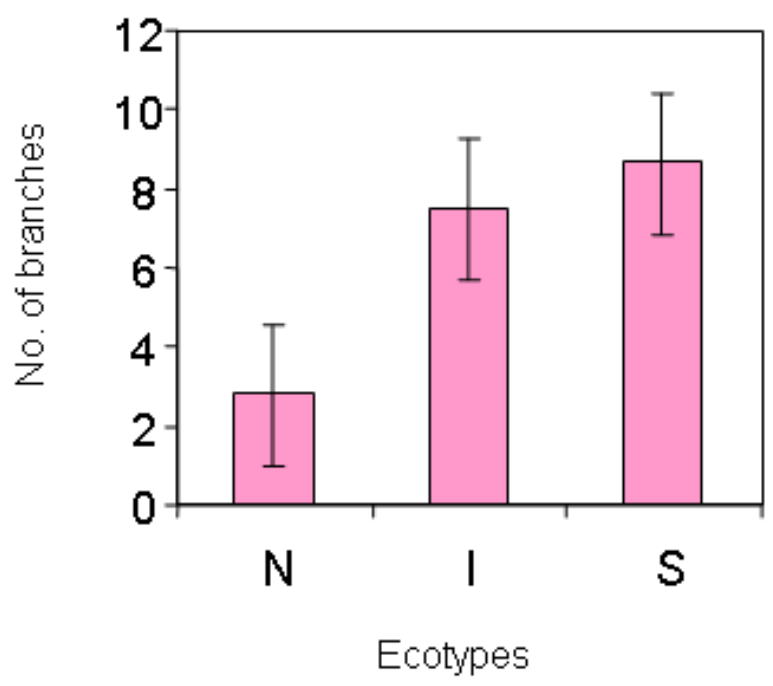

Figure 5. Number of branches produced by ecotypes of $B$. pendula grown in LD, $12 \mathrm{hrs}$ of PAR $\left(150 \mu \mathrm{mol} \mathrm{m} \mathrm{m}^{-2} \mathrm{~s}^{-1}\right.$ fluorescent plus $10 \mu \mathrm{mol} \mathrm{m} \mathrm{m}^{-2} \mathrm{~s}^{-1}$ ) during the day and $12 \mathrm{hrs}$ of incandescent light $\left(10 \mu \mathrm{mol} \mathrm{m} \mathrm{m}^{-2} \mathrm{~s}^{-1}\right)$ during the light extension period (night). Each point is a mean of 16 plants. Mean \pm S.E. are shown. No branching was seen when the daylength was extended with monochromatic R or FR or with their mixtures.

In conclusion, $\mathrm{R}$ and $\mathrm{FR}$ at higher intensities influenced shoot elongation differently. FR at about $9.5-25 \mu \mathrm{mol} \mathrm{m}{ }^{-2}$ $\mathrm{s}^{-1}$ sustained continuous elongation of shoots of all ecotypes compared to R. However, the combined effect of R and FR at various ratios and at an intensity of $25 \mu \mathrm{mol} \mathrm{m} \mathrm{m}^{-2}$ had a significantly higher effect. This clearly showed the combined effect of phyA and phyB in all B. pendula ecotypes.

\section{ACKNOWLEDGEMENTS}

The authors are grateful to the staff of the Climate Laboratory, University of Tromso, for offering us their facility for so long time. Mr. Tsefaye Dagnew, a senior lecturer of English at Bahir Dar University, is also duly acknowledged for his language editorial service.

\section{REFERENCES}

BERHANU ABRAHA, T. Growth responses of Betula pendula ecotypes to photoperiod, light quality and light intensity with special emphasis to gibberellins. Doctoral thesis. Department of Plant Physiology and Microbiology, 
University of Tromsø, Norway. December 2002. 158 p. ISBN 82-92461-00-0.

CHORY, J. Light modulation of vegetative development. Plant Cell, 1997, vol. 9, no. 7, p. 1225-1234.

CLAPHAM, D.H.; DORMLING, I.; EKBERG, I.; ERIKSSON, G.; QAMARUDDIN, M. and VINCE-PRUE, D. Latitudinal cline of requirement for far-red light for the photoperiodic control of bud set and extension growth in Picea abies (Norway spruce). Physiologia Plantarum, 1998, vol. 102, no. 1, p. 71-78.

CLAPHAM, D.H.; EKBERG, I.; EIRKSSON, G.; NORELL, L. and VINC-PRUE, D. Requirement for far-red light to maintain secondary needle extension growth in northern but not southern populations of Pinus sylvestris (Scots pine). Physiologia Plantarum 2002,. Vol. 114, no. 2, p. 207-212.

GIL, P.; KIRCHER, S.; ADAM, E.; BURY, E.; KOZMABOGNAR, L.; SCHAFER, E. and NAGY, F. Photocontrol of subcelluar partitioning of phyotchrome B:GFP fusion protein in tobacco seedlings. The Plant Journal, 2000, vol. 22, no. 2, p. 135-145.

HAUSER, B.A.; PRATT, L.H. and CORDONNIERPRATT, M.M. Absolute quantification of five phytochrome transcripts in seedlings and mature plants of tomato (Solanum tubersum L.). Planta, 1997, vol. 201, no. 3, p. 379-387.

HAYCOCK, K.A.; ROTH, J. and GAGNON, J. Manual for Stat View. Abacus concepts, Inc. $2^{\text {nd }}$ ed. 1018 Bonita Avenue, Berkeley, CA 94704-1014. 1994. 466 p. ISBN 0944800-03-3.

HÅBJØRG, A. Effects of light quality, light intensity, and night temperature on growth and development of three latitudinal populations of Betula pubescens. Meldinger Norges Landbrukskole, 1972, vol. 51, no. 44, p. 1-17.

IMAIZUMI, T.; KADOTA, A.; HASEBE, M. and WADA, M. Cryptochrome light signals control development to suppress auxin sensitivity in moss Physcomitrella patens. Plant Cell, 2002, vol. 14, no. 2, p. 373-386.

JOHNSEN, Ø. and SKRØPPA, T. Adaptive properties of Picea abies progenies are influenced by environmental signals during sexual reproduction. Euphytica, 1996, vol. 92, no. 1-2, p. 67-71.

JOHNSEN, Ø.; SKRØPPA, T.; JUNTTILA, O. and DAEHLEN, O. Influence of female flowering environment on autumn frost-hardiness of Picea abies progenies. Theoretical and Applied Genetics, 1996, vol. 92, no. 7, p.
797-802.

JUNTTILA, O. and KAURIN, Å. Climatic control of apical growth cessation in latitudinal ecotypes of Salix pentandra L. In: KÅURIN, Å.; JUNTTILA, O. and NILSEN, J. eds. Plant Production in the North. Norwegian University Press, Oslo, 1985. p. 83-91.

JUNTTILA, O. Effect of photoperiod and temperature on apical growth cessation in two ecotypes of Salix and Betula. Physiologia Plantarum, 1980, vol. 48, p. 347-352.

OLSEN, J.E. and JUNTTILA, O. Far red end-of-day treatment restores wild type-like plant length in hybrid aspen overexpressing phytochrome A. Physiologia Plantarum, 2002, vol. 115, no. 3, p. 448-457.

OLSEN, J.E.; JUNTTILA, O.; NILSEN, J.; ERIKSSON, M.; MARTINUSSEN, I.; OLSSON O.; SANDBERG, G. and MORITZ, T. Ectopic expression of phytochrome A in hybrid aspen changes critical day-length for growth and prevents cold acclimation. The Plant Journal, 1997, vol. 12, no. 6, p. 1339-1350.

SKRØPPA, T. and JOHNSEN, Ø. Patterns of adaptive genetic variation in forest tree species; the reproductive environment as an evolutionary force in Picea abies. In: MÅTYÅS, C. ed. Forest Genetics and Sustainability. Kluwer Academic Publishers, The Netherlands, 2000, vol. 63, p. 49-58.

TAIZ, L. and ZEIGER, E. Plant Physiology. Benjamin/Cummings Publishing Co. Inc., California. 1998, p. 792.

WELLER, J.L.; SCHREUDER, M.E.L.; SMITH, H.; KOORNNEEF, M. and KENDRICK, R. E. Physiological interactions of phytochromes $\mathrm{A}, \mathrm{B}_{1}$ and $\mathrm{B}_{2}$ in the control of development in tomato. Plant Journal, 2000, vol. 24, p. 345-356. 